\title{
ATIVIDADE LÚDICA: UM DESAFIO PARA O ENSINO DE QUÍMICA NO CONTEÚDO DE FUNÇÃO INORGÂNICA (ÁCIDOS)
}

\section{LONDON ACTIVITY: A CHALLENGE FOR THE EDUCATION OF CHEMISTRY IN THE CONTENT OF INORGANIC FUNCTION (ACIDS)}

\author{
Ayrton Matheus da Silva Nascimento ${ }^{1}$; Danielly Francielly dos Santos Silva ${ }^{2}$; Gabriela \\ Rejane Silva de Medeiros ${ }^{3}$; Natália Kelly da Silva Araújo ${ }^{4}$; Kilma da Silva Lima Viana ${ }^{5}$
}

\section{RESUMO}

Utilizar jogos didáticos nas aulas de ciência da natureza é uma vivência desafiadora, especificamente para a disciplina de Química, pois é necessário criar uma sinapse entre o lúdico e a teoria, inserindo simbologia, imagens, nomenclaturas, fórmulas e palavras-chaves para interligar os tópicos conceituais. Esta pesquisa mostra a elaboração até a experiência de um jogo didático, chamado "A Procura do Ácido" utilizando como metodologia o CEK (Ciclo da Experiência Kellyana) proposto por George Kelly (1963). Este jogo é direcionado para os estudantes do Ensino Fundamental II ( $9^{\circ}$ Ano) e/ou do Ensino Médio, no conteúdo de Funções Inorgânicas priorizando a função "ácidos", onde tem o intuito de identificar (i) o número de hidrogênios ionizáveis, (ii) número de elementos, (iii) presença de oxigênio, (iv) força dos ácidos e (v) nomear o ácido. Este objeto de ensino foi idealizado pelo Instituto Internacional Despertando Vocações (IIDV) ligado ao Programa Internacional Despertando Vocações para Licenciaturas (PDVL) articulado ao Grupo de Trabalho (GT) de Jogos Didáticos no Ensino de Química, e a experiência foi realizada numa turma de $9^{\circ}$ ano do ensino fundamental II do Colégio Projeção, na qual é parceira do programa, na cidade Vitória de Santo Antão Pernambuco. Desse modo, utilizamos como estrutura metodológica o ciclo da experiência Kellyana (CEK) o qual é embasado pela Teoria dos Construtos Pessoais de George Kelly (1963). Assim sendo, foi aplicado a atividade lúdica com os estudantes e aplicados questionários sobre a vivência do Ciclo da Experiência. Os dados obtidos foram alcançados empregando o CEK, na qual discerni na primeira etapa alguns erros de conceitos referentes as classificações e nomenclaturas dos ácidos, na explanação do conteúdo (segunda etapa) foi elencados alguns ácidos para identificação e nomeação, na terceira etapa na vivência da atividade lúdica foram bastantes oportuno, pois identificamos algumas características lúdicas, já na quarta etapa (confirmação ou desconfirmação) foram ápices de acertos e erros onde foram inseridos alguns ácidos para os estudantes responderem e perceberem que a vivência com o lúdico oportunizou a aprender e compreender os conceitos químicos, e foi notório que $93 \%$ dos alunos responderam os exemplos, e por fim, teve o momento de reflexões onde podemos perceber que os estudantes gostaram do momento lúdico, e que a apropriação do conceito básico foram reavaliados e afirmados, com o intuito de solidificar as ideias adquiridas na intervenção.

Palavras-Chave: Funções Inorgânicas, Ácidos, CEK, Jogo Didático, Ensino Fundamental II

\begin{abstract}
\footnotetext{
${ }^{1}$ Especialista em Ensino de Química, UCAM - Prominas, ayrthon.matheus@ gmail.com

${ }^{2}$ Graduanda em Química, IFPE - Campus Vitória, danysantos023@ outlook.com

${ }^{3}$ Graduanda em Química, IFPE - Campus Vitória, medeirosgabriela32@ yahoo.com.br

${ }^{4}$ Graduanda em Química, IFPE - Campus Vitória, nataliakellybs@ gmail.com

${ }^{5}$ Doutora em Ensino de Ciências, IFPE - Campus Vitória, kilma.viana71@ gmail.com
}

To use didactic games in the classes of science of the nature is a challenging experience, specifically for the discipline of Chemistry, since it is necessary to create a synapse between the ludic and the theory, inserting symbology, images, nomenclatures, formulas and keywords to interconnect the topics concepts 
This research shows the elaboration until the experience of a didactic game, called "The Search for Acid" using as a methodology the CEK (Kellyana Experiment Cycle) proposed by George Kelly (1963). This game is directed to the students of Elementary School II (9th Grade) and / or High School, in the content of Inorganic Functions prioritizing the function "acids", in order to identify (i) the number of ionizable hydrogens, ii) number of elements, (iii) presence of oxygen, (iv) strength of acids and (v) naming the acid. This teaching object was conceived by the International Institute for Awakening Vocations (IIDV) linked to the International Program for Vocational Education and Training (PDVL) articulated to the Teaching Games Working Group (GT) in Chemistry Teaching, and the experience was carried out in a group of 9 year of elementary school II of the College Projection, in which she is a partner of the program, in the city Vitória de Santo Antão - Pernambuco. Thus, we use as a methodological framework the Kellyana experience cycle (CEK), which is based on George Kelly's Theory of Personal Constructs (1963). Therefore, it was applied the play activity with the students and applied questionnaires on the experience of the Experience Cycle. The obtained data were obtained using the CEK, in which the first stage detected some errors of concepts referring to the classifications and nomenclatures of the acids, in the explanation of the content (second stage) were listed some acids for identification and naming, in the third stage in the experience of the In the fourth stage (confirmation or disconfirmation) were apices of correct answers and errors where some acids were inserted for the students to respond and to perceive that the experience with the ludic gave the opportunity to learn and understand the and it was notorious that $93 \%$ of the students answered the examples, and finally, there was the moment of reflection where we can perceive that the students liked the playful moment, and that the appropriation of the basic concept was reassessed and affirmed, with the intention to solidify the ideas acquired in the intervention.

Keywords: Inorganic Functions, Acids, CEK, Didactic Game, Elementary School II

\section{INTRODUÇÃO}

Os jogos didáticos são caracterizados como uma ferramenta coadjuvante no processo de ensino e aprendizagem da química no nível de ensino médio, pois tem como finalidade aliar o aprendizado e a fixação de um determinado conteúdo à atividade lúdica despertando assim o interesse por aprender algo que foi proposto e este relacionado ao jogo. A interação do lúdico com o educativo, ou seja, com os conteúdos da disciplina tornam-se ferramentas importantes no desenvolvimento das atividades propostas em um ambiente competitivo e altamente saudável (ROBAINA, 2008).

Cada vez mais a sociedade exige estudantes críticos, reflexivos, que se posicionem, julguem e tomem decisões, e que sejam responsabilizados por isso (BRASIL, 2006), no entanto, historicamente, no ensino da Química, as práticas estão relacionadas com as abordagens tradicionais de ensino (LIMA, 2008; MIZUKAMI, 1986),

Nesta esfera, uma das estratégias de aprendizagem são os jogos didáticos, tal recurso

pode promover a construção do conhecimento, interação, socialização, além do desenvolvimento de diversas habilidades a partir de um ambiente descontraído. Conforme Souza et al (2010), o jogo e a brincadeira estão presentes em todas as fases da vida dos seres 
humanos, tornando especial a sua existência, além de ser elementos muito valiosos no processo de apropriação do conhecimento, pois permitem o desenvolvimento de competências no âmbito da comunicação, relações interpessoais, liderança e trabalho em equipe.

Diante disto, este trabalho tem a intenção de abordar uma intervenção com um jogo didático intitulado: “A Procura do Ácido", é válido destacar que esta experiência foi com os estudantes do $9^{\circ}$ ano do Ensino Fundamental II, na escola parceira do PDVL (Programa Internacional Despertando Vocações para Licenciaturas), localizada no município de Vitória de Santo Antão. Esta pesquisa tem o objetivo desta atividade lúdica é identificar alguns tópicos conceituais (TC) referente a função inorgânica (ácidos).

\section{FUNDAMENTAÇÃO TEÓRICA}

Dentre várias atividades propostas, vem se destacando o uso de jogos e atividades lúdicas, descritos frequentemente na literatura (Oliveira; Soares, 2005; Santos; Michel, 2009; Benedetti Filho et al., 2009; Nascimento et al., 2015, Nascimento e Viana, 2016). Tais alternativas são desenvolvidas pelo forte apelo motivacional para os alunos de nível médio, o que pode levar ainda ao aumento da concentração e do estímulo ao raciocínio como nos aponta Oliveira e Soares (2005, p. 19).

Em particular no ensino da Química, percebe-se que os discentes, muitas vezes, não conseguem aprender, tampouco, capazes de associar o conteúdo estudado com seu cotidiano, tornando-se desinteressados pelo tema. Isto indica que este ensino está sendo feito de forma descontextualizada, não interdisciplinar e sem variedade no que concernem as metodologias de ensino (NUNES e ADORNI, 2010).

É perceptível a falta de motivação dos alunos que quase sempre é pela falta de metodologia do professor, tornando os conteúdos extensos e nada atrativos. Atualmente os jogos didáticos estão sendo utilizados como proposta facilitadora na aprendizagem dos conceitos. O jogo pode ser utilizado como um material didático inovador para facilitar e minimizar as notas baixas no componente curricular de Química (ARAÚJO, 2016).

É válido ressaltar, porém, que os jogos educativos se limitam como objetos de aprendizagem alternativos, requerendo previamente para sua eficácia que os estudantes tenham conhecimento do conteúdo abordado para favorecer o desenvolvimento físico, cognitivo, afetivo, social e moral (KISHIMOTO, 2009).

A precípua utilidade do uso de jogos didáticos envolve a motivação, desenvolvida pelo desafio, acarretando o acréscimo de estratégias de resolução de dúvidas, a avaliação das decisões tomadas e a familiarização com termos e concepções apresentadas. Os jogos 
pedagógicos aliam o aprendizado de determinados conteúdos à atividade lúdica, despertando interesse dos educandos nos conteúdos discutidos e propiciando uma aprendizagem eficaz, divertida e empolgante. Por esse motivo, o jogo se torna uma peça de importância quando se quer atrair a atenção do aluno para determinado conteúdo em que ele oferece resistência. No momento em que ele encara o jogo como uma brincadeira, aprende o conteúdo sem perceber. (KISHIMOTO, 1994).

\section{METODOLOGIA}

Esta pesquisa foi desenvolvida pelo Instituto Internacional Despertando Vocações (IIDV) ligado ao Programa Internacional Despertando Vocações para Licenciaturas (PDVL) articulado ao Grupo de Trabalho (GT) de Jogos Didáticos no Ensino de Química e dos professores da área Pedagógica do programa.

\section{Caracterização do Campo da Pesquisa}

A pesquisa foi concretiza na escola parceira do PDVL no Colégio Projeção, na Cidade de Vitória de Santo Antão, no estado de Pernambuco. Os sujeitos foram 41 (quarenta e um) estudantes do $9^{\circ}$ ano do ensino fundamental II.

\section{Instrumentos de Coleta}

Foram empregados como instrumentos de pesquisa questionário com os discentes, observação e registro da vivência do Ciclo da Experiência Kellyana - CEK, (KELLY, 1955). Com isso, utilizamos como base metodológica o ciclo da experiência Kellyana (CEK) o qual é fundamentado na Teoria dos Construtos Pessoais de George Kelly (1963).

\section{Aplicação do Ciclo da Experiência Kelly (CEK) - "A Procura do Ácido"}

- Antecipação: nesta etapa foi realizada o levantamento dos conhecimentos prévios dos estudantes, onde eles foram questionados a identificarem nos elementos abaixo as seguintes informações conceituais: (i) o número de hidrogênios ionizáveis, (ii) número de elementos, (iii) presença de oxigênio, (iv) força dos ácidos e (v) nomear o ácido.

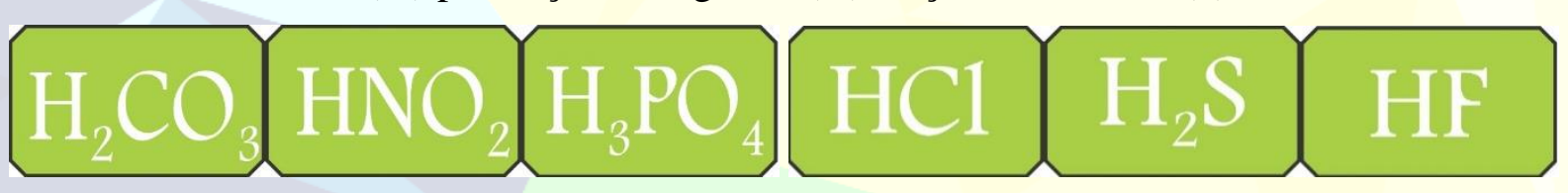

Figura 01: Elementos para identificar as informações conceituais - Fonte: Própria

- Na segunda etapa, chamada de Investimento, é explanado o conteúdo, onde foram citados alguns exemplos para identificar alguns tópicos conceituais sobre ácidos. 
- A terceira etapa do CEK, chamada de Encontro, neste momento os estudantes receberam as diretrizes do Jogo Didático - “A Procura do Ácido” e vivenciar o jogo.

- A quarta etapa, chamada de Confirmação ou Desconfirmação, é quando os discentes são direcionados a confirmar ou desconfirmar as suas ideias iniciais referente a temática de função inorgânica (ácidos) respondendo os elementos para identificar as informações conceituais

- No encerramento desse ciclo, foi concretizado a quinta etapa, a chamada de Revisão Construtiva, nessa etapa os sujeitos são direcionados a refletirem a respeito da temática, e suas características, e as divergência entre os ácidos.

\section{DESCRIÇÃO DO JOGO - "A Procura do Ácido"}

Esse jogo didático tem o intuito de identificar as características e nomear a função inorgânica "Ácidos", seja qual for o ácido, de forma lúdica e animada. O jogo é composta por 05 (cinco) estágios, onde cada estágio é atribuído uma característica no jogo referente ao conteúdo de Função Inorgânica (Ácidos). Para identificar o ácido é necessário que tenha como embasamento o estudo de Reis (2015), e uma tabela de cátions e ânions. Utilizamos como orientação para construção deste jogo os estudos de Reis (2015).

Abaixo segue os estágios e a pontuação do jogo:

$\checkmark \quad 1^{0}$ Estágio (vale 20 pontos): é classificar os ácidos pela quantidade de hidrogênios ionizáveis;

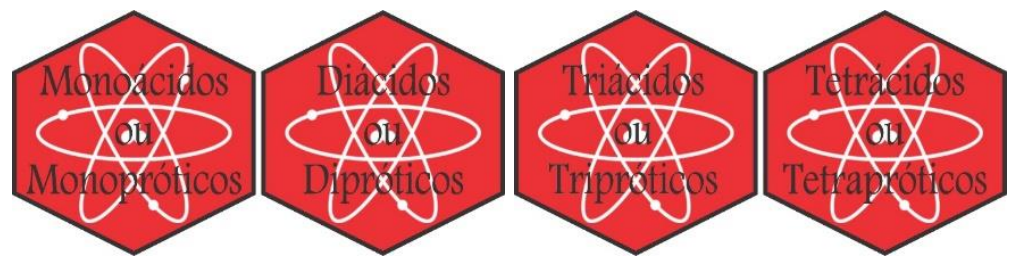

$\checkmark \quad 2^{\circ}$ Estágio (10 pontos): é numerar os elementos químicos que cada ácido apresenta;

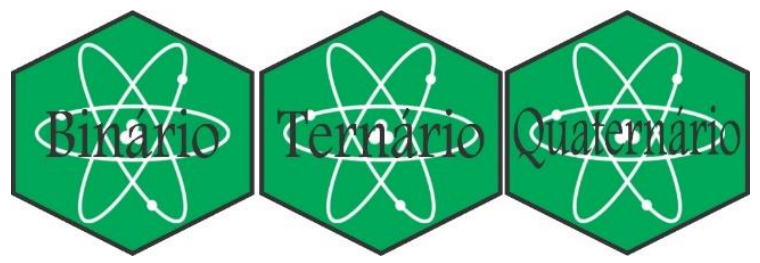

$\checkmark \quad 3^{\circ}$ Estágio (10 pontos): é a presença ou a ausência de oxigênio;

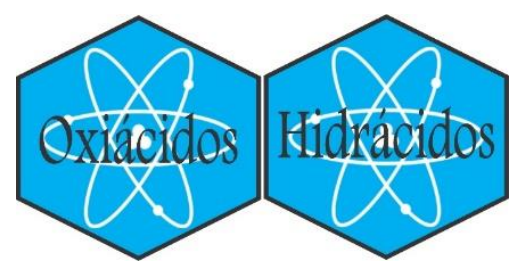

$\checkmark \quad 4^{\circ}$ Estágio (20 pontos): é a força dos ácidos; 


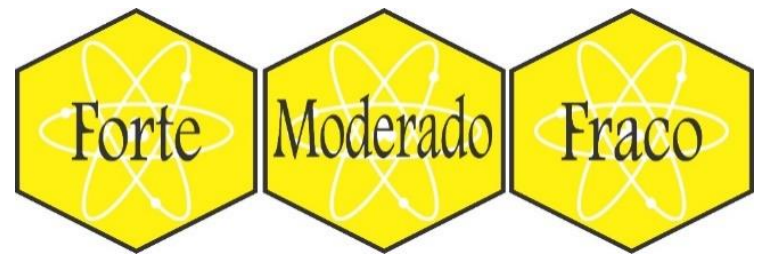

$\checkmark \quad 5^{\circ}$ Estágio (40 pontos): é a nomeação dos ácidos;

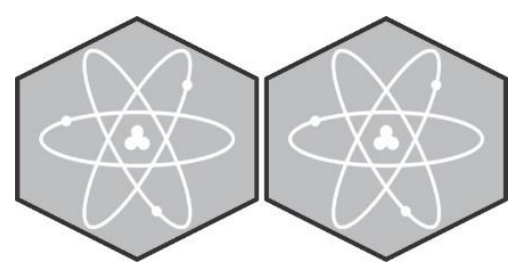

\section{CARTAS DOS ÁCIDOS}

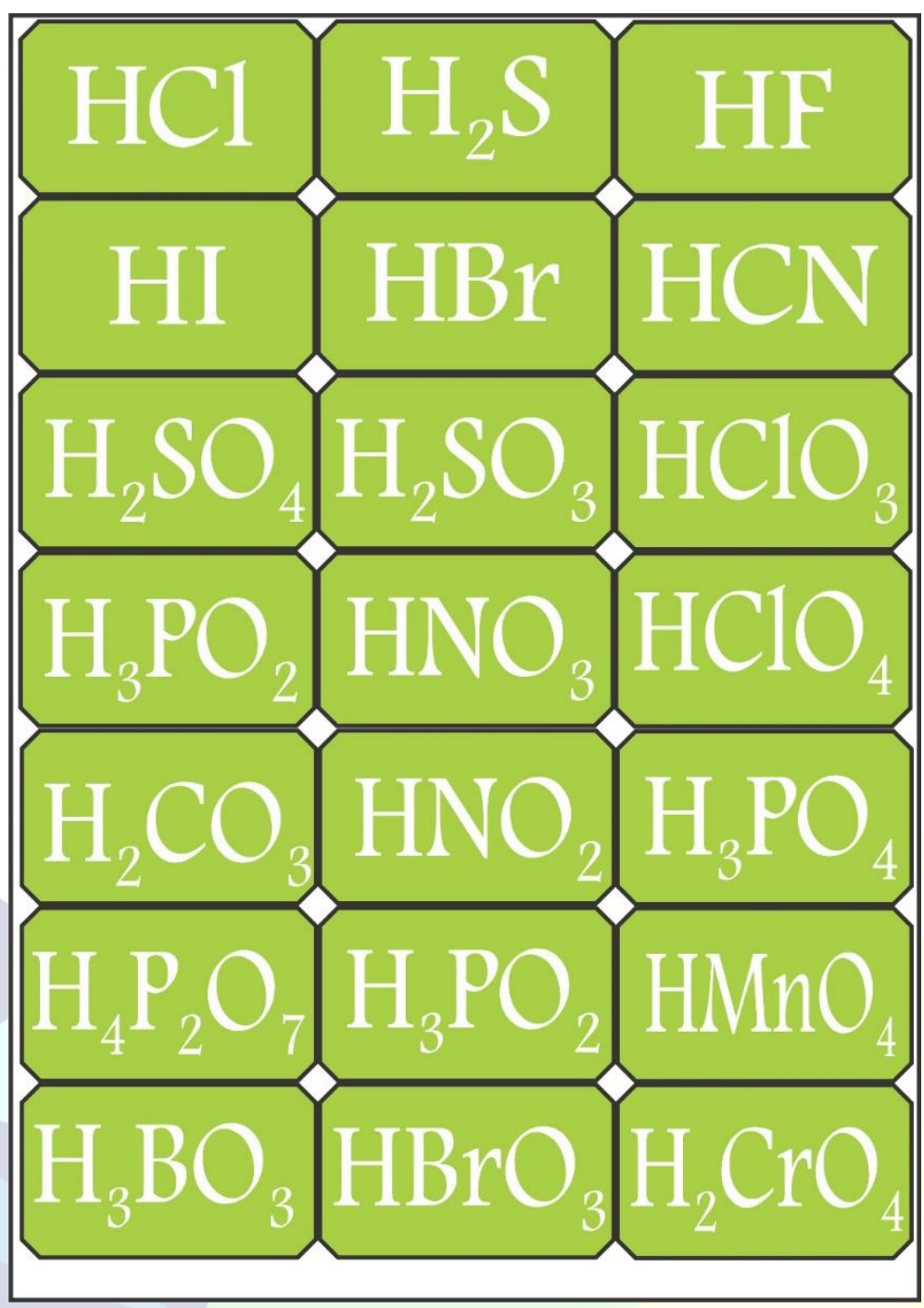

\section{Regra do Jogo}

Segue abaixo as orientações de formação de grupos por quantidade de alunos:

$\checkmark$ Após a divisão 04 (quatro) grupos, cada integrante irá se descolar para uma cadeira;

$\checkmark$ Todos receberão placas do $1^{\circ}$ estágio até $5^{\circ}$ estágio, onde o primeiro vale 20 (vinte) pontos por acertos e é classificar os ácidos pela quantidade de hidrogênios ionizáveis como 
(monoácido ou monoprótico), (diácido ou diprótico), (triácido ou triprótico) e (tetrácido ou tetraprótico), já o segundo estágio vale 10 (dez) pontos por acertos e é classificar o ácido pelo quantidade de elementos químicos como (binário), (ternário) e (quaternário), já o próximo vale $10(\mathrm{dez})$ pontos por acertos e é referente a presença ou a ausência de oxigênio como (hidrácidos e oxiácidos), já no quarto estágio vale 20 (vinte) pontos por acertos e é direcionado a força dos ácidos como (fraco), (moderado) ou (forte) e o último estágio vale 40 (quarenta) pontos e é referente a nomenclatura dos ácidos.

$\checkmark$ Para cada estágio os estudantes terão 20 (segundos) para responder, já no último estágio 60 (sessenta) segundos;

$\checkmark$ Primeiro escolhe um cartão do ácido, e informa os jogadores, e para cada estágio terão 20 (segundos), primeiro identifica o número de hidrogênios ionizáveis, (ii) número de elementos, (iii) presença de oxigênio, (iv) força dos ácidos e neste estágio (v) nomear o ácido tem 60 (sessenta) para responder;

$\checkmark$ Após passar por todos os estágios, tira outro cartão do ácido, e repete todo processo acima;

$\checkmark$ Registrando os acertos e erros de cada estudante;

$\checkmark$ Em seguida, faz a troca de estudantes e segue o mesmo procedimento;

$\checkmark$ Ao término das rodadas, verifica-se qual(is) estudante(s) acertou mais características dos ácidos, e com os erros, mostrar como solucionar, o intuito não é vencedor, e sim, aquele que aprender mais.

\section{Placas do jogo}

Abaixo segue as placas para execução do jogo, é necessário que cada pessoa receba todas as placas contendo todas as informações:

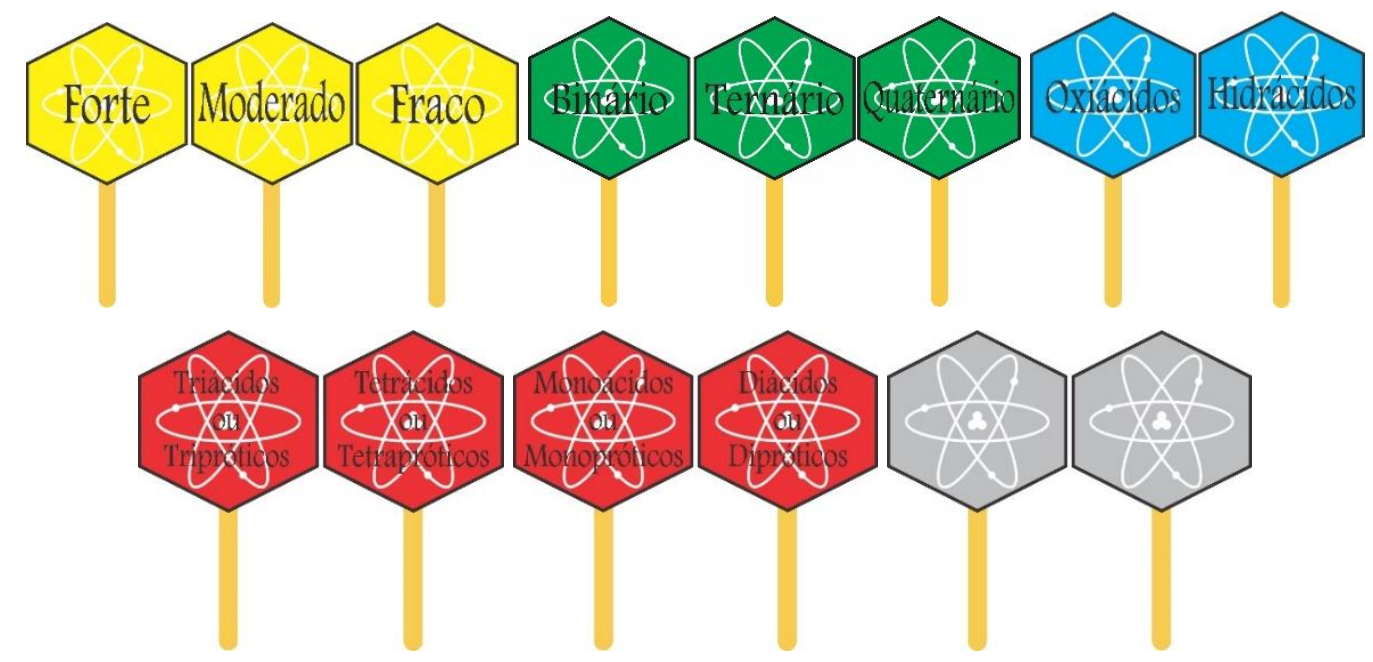




\section{RESULTADOS E DISCUSSÃO}

\section{Vivência do Ciclo da Experiência Kellyana (CEK) - Roletas da Distribuição Eletrônica}

Durante a experiência do ciclo foram verificados alguns pontos de caráter prático que beneficiaram as ideias dos estudantes referente a função inorgânica (ácidos). Abaixo segue detalhadamente as discussões vivência

$\mathrm{Na}$ Antecipação, dar-se-a início ao ciclo da experiência, onde os discentes foram direcionados aos problemas contendos 06 (seis) exemplos de ácidos para identificarem os tópicos conceituais, constituindo eles da figura 01 .
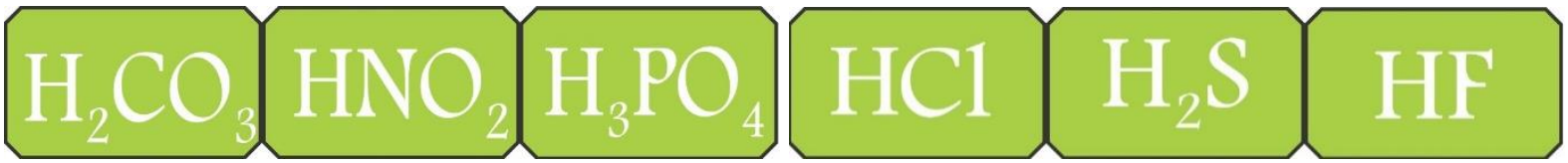

A turma apresenta 41 (quarenta e um) alunos,

Tabela 01: Quantitativos de acertos e erros - $4^{\mathrm{a}}$ etapa do CEK - Fonte: Própria

\begin{tabular}{c|c|c|c|c|c|c|c|c|c|c} 
& \multicolumn{2}{|c|}{ TC (i) } & \multicolumn{2}{c|}{ TC (ii) } & \multicolumn{2}{c|}{ TC (iii) } & \multicolumn{2}{c}{ TC (iv) } & \multicolumn{2}{c}{ TC (v) } \\
\cline { 2 - 12 } & ACERTOS & ERROS & ACERTOS & ERROS & ACERTOS & ERROS & ACERTOS & ERROS & ACERTOS & ERROS \\
\hline Ácido I & 22 & 19 & 28 & 13 & 20 & 21 & 32 & 09 & 35 & 06 \\
\hline Ácido II & 18 & 23 & 25 & 16 & 16 & 25 & 28 & 13 & 32 & 09 \\
\hline Ácido III & 23 & 18 & 29 & 12 & 18 & 23 & 30 & 11 & 38 & 03 \\
\hline Ácido IV & 26 & 13 & 29 & 12 & 19 & 24 & 31 & 10 & 34 & 07 \\
\hline Ácido V & 14 & 27 & 31 & 10 & 17 & 24 & 29 & 12 & 35 & 06 \\
\hline Ácidos VI & 17 & 24 & 28 & 13 & 14 & 27 & 26 & 15 & 33 & 08
\end{tabular}

Tópicos conceituais (TC): (i) o número de hidrogênios ionizáveis; (ii) número de elementos; (iii) presença de oxigênio; (iv) força dos ácidos; (v) nomear o ácido.

No TC (i) é referente ao número de hidrogênios ionizáveis e os alunos erraram mais no ácido IV devido a quantidade de átomos, já no TC (ii) é sobre o número de elementos erraram mais no ácido $\mathrm{V}$, no TC (iii) e quanto a presença ou ausência de oxigênio erraram mais no ácido I, no TC (iv) é referente as forças dos ácidos e não acertaram no ácido I e no TC (v) é sobre a nomenclatura dos ácidos, a maioria erradam no ácido III.

No Investimento foi trabalhado em cima das difuldades dos elementos, onde foram elencados alguns ácidos para classificarem baseados aos tópicos conceiturais.

No Encontro da vivência da atividade lúdica, os discentes foram orientados baseado na leitura da regra do jogo. Esta etapa teve em média 50 (cinquenta) minutos. No momento do jogo (encontro) os estudantes interagiram entre si, e mostraram bastante interação entre jogoestudante e estudante-estudante, Desse modo, é importante salientar que Vygotsky (1987, p. 149) afirma que “o jogo é considerado um estímulo à criança no desenvolvimento de processos 
internos de construção do conhecimento e no âmbito das relações com os outros". Mais uma vez, por mais que muitos estudiosos tratem do processo de aprendizagem da criança, suas ideias não fazem restrições apenas a uma faixa etária específica. Com isso, podemos perceber que a utilização da atividade lúdica como recurso didático é de suma importância, pois como visto antes com Kishimoto (1998), o jogo didático apresenta função lúdica e educativa, sendo assim, os discentes podem aprender os conceitos de forma mais atraente de modo que, se fundamentem cada vez mais em suas definições, contribuindo para com o ensino-aprendizagem.

Figura 09: Vivência da atividade lúdica - Fonte: Própria

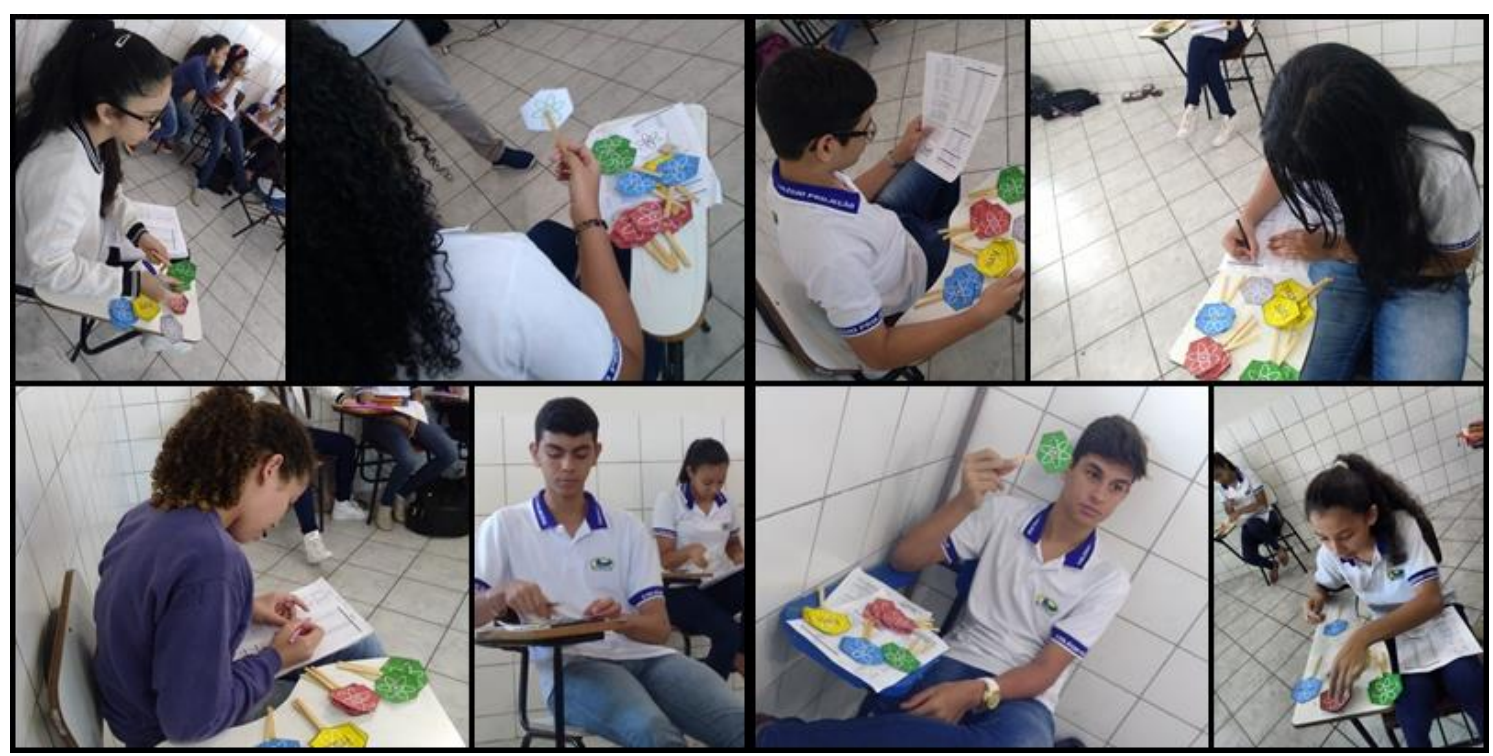

Na Confirmação ou Desconfirmação verifica-se as ideias dos estudantes referente aos

TC dos ácidos, com isso, utilizamos os experimentos da antecipação, e foi solicitado para os estudantes identificarem os 05 (cinco) TC, e averiguá-se a atividade lúdica coopera para a aprendizagem dos estudantes e o jogo com o papel fundamental de estimular os estudantes e aproximação dos conceitos.

Tabela 02: Quantitativos de acertos e erros - 4 etapa do CEK - Fonte: Própria

\begin{tabular}{c|c|c|c|c|c|c|c|c|c|c} 
& \multicolumn{2}{|c|}{ TC (i) } & \multicolumn{2}{c|}{ TC (ii) } & \multicolumn{2}{c|}{ TC (iii) } & \multicolumn{2}{c}{ TC (iv) } & \multicolumn{2}{c}{ TC (v) } \\
\cline { 2 - 12 } & ACERTOS & ERROS & ACERTOS & ERROS & ACERTOS & ERROS & ACERTOS & ERROS & ACERTOS & ERROS \\
\hline Ácido I & 39 & 02 & 35 & 06 & 40 & 01 & 40 & 01 & 36 & 05 \\
\hline Ácido II & 37 & 04 & 40 & 01 & 39 & 02 & 36 & 05 & 40 & 01 \\
\hline Ácido III & 40 & 01 & 35 & 06 & 36 & 05 & 38 & 03 & 40 & 01 \\
\hline Ácido IV & 38 & 03 & 36 & 05 & 40 & 01 & 39 & 02 & 38 & 03 \\
\hline Ácido V & 40 & 01 & 33 & 08 & 36 & 05 & 35 & 06 & 40 & 01 \\
\hline Ácidos VI & 40 & 01 & 36 & 05 & 35 & 06 & 39 & 02 & 39 & 02
\end{tabular}

Tópicos conceituais (TC): (i) o número de hidrogênios ionizáveis; (ii) número de elementos; (iii) presença de oxigênio; (iv) força dos ácidos; (v) nomear o ácido. 
No TC (i) é referente ao número de hidrogênios ionizáveis e os alunos acertaram mais no ácido III, V e VI devido a quantidade de átomos, já no TC (ii) é sobre o número de elementos acertaram mais no ácido II, no TC (iii) e quanto a presença ou ausência de oxigênio acertaram mais no ácido I e IV, no TC (iv) é referente as forças dos ácidos e acertaram no ácido I e no TC (v) é sobre a nomenclatura dos ácidos, a maioria acertaram nos ácidos II, III e V. Os resultados coletados foram analisados pelo estudo de Reis (2015).

Nota-se que com a atividade lúdica trouxe vários resultados para os estudantes, entre eles o lúdico e o educativo, onde Kishimoto (1996), o primeiro remete a ideia dos prazer, da diversão, já o educativo vincula-se ao aprendizagem de conceitos.

Na Revisão Construtiva foi realizado um momento de conversação onde verificamos alguns tópicos abaixo:

(i) Como vocês observam a importância do jogo didático para aula?

Sujeito 01: "é mas fácil para aprender".

Sujeito 03: "o ácido é muito detalhado e com o jogo ficou mais fácil".

(ii) Conseguiram envolver no assunto de função inorgânica (ácidos)?

Sujeito 05: "com este jogo ficou mas divertido de aprender o conteúdo".

Sujeito 06: "consegue aprender a nomenclatura".

\section{CONCLUSÕES}

Conclui-se que a atualização de jogos didáticos é significativa, os alunos se encontras mais estimulados para estudar os conteúdos de química. A atividade lúdica teve a finalidade atingida, como (i) o número de hidrogênios ionizáveis, (ii) número de elementos, (iii) presença de oxigênio, (iv) força dos ácidos e (v) nomear o ácido. Outro tópico relevante é que, empregar os Jogos Didáticos consente ao docente a trabalhar em cima dos erros conceituais dos alunos, além de mostrar um momento prazeroso, e ser usado pelos profissionais da educação como auxílio didático.

Pode-se notar que o TC (i) o ácido V teve um aumento significativo mostra o número de hidrogênios ionizáveis, já no TC (ii) o ácido II teve um acréscimo de acertos referente ao número de elementos, no TC (iii) o ácido II e VI teve uma ampliação sobre a presença ou ausência de oxigênio, no TC (iv) o ácido VI teve uma aumento referente a força dos ácidos e no TC (v) o ácido II conseguiram aumentar a quantidade de acertos sobre a nomenclatura da função inorgânica (ácidos). 
O jogo entusiasma e desperta o raciocínio dos estudantes e a afinidade entre aluno e professor, entre teoria e prática, as aulas de química ficam mais interessantes, divertidas e descontraídas. Uma metodologia inovadora, que busca esse novo olhar para o desenvolvimento das aulas de química pode fazer a diferença na aprendizagem de cada sujeito.

Este artigo mostrou o quão importante é que o docente busque sempre novas ferramentas de ensino procurando diversificar suas aulas e assim torná-las mais interessantes e atraentes para seus alunos, e o trabalho com jogos didáticos vem atender essa necessidade como opção diferenciada, que pode ser utilizada como reforço de conteúdos previamente desenvolvidos.

\section{REFERÊNCIAS}

ARAÚJO, N. K. S., SANTANA, M. V. F. S.; NASCIMENTO, A. M. S.; ARAUJO, R. G. B.; VIANA, K. S. L. Roleta Atômica: Um Jogo Didático no Ensino de Química Elencando Através do Ciclo da Experiência Kellyana. In: III Congresso Nacional de Educação, 2016, Natal - RN. Anais do III Congresso Nacional de Educação.

ARAÚJO, R. G. B., NASCIMENTO, A. M. S.; VIANA, K. S. L. Baralhos dos Hidrocarbonetos: Uma Proposta de Metodologia Inovadora para o Ensino no Conteúdo de Química Orgânica. In: III Congresso Nacional de Educação, 2016, Natal - RN. Anais do III Congresso Nacional de Educação.

BENEDETTI FILHO, E.; FIORUCCI, A.R.; BENEDETTI, L.P.S.; CRAVEIRO, J.A. Palavras cruzadas como recurso didático no uso de teoria atômica. Química Nova na Escola, v. 31, n. 2, p. 88-95, 2009.

BRASIL. Orientações curriculares para o ensino médio - Ciências da natureza, matemática e suas tecnologias. Brasília: Ministério da Educação, Secretaria de Educação Básica, 2006.

KELLY, G. A. A theory of personality: the psychology of personal constructs. New York: W.W. Norton, 1963.

KELLY, G. A. The psychology of personal constructs. Vols. 1 e 2. New York: Norton, 1955.

KISHIMOTO, T. M. Jogo, Brinquedo, Brincadeira e a Educação. São Paulo: Cortez, 1996. $183 p$.

LIMA, K. S. Compreendendo as concepções de avaliação de professores de Química através da teoria dos construtos pessoais. 163f. 2008. Dissertação (Ensino das Ciências).

Departamento de Educação, Pró-Reitoria de Pesquisa e Pós-Graduação, Universidade Federal Rural de Pernambuco, Recife, 2008.

MIZUKAMI, M. G. N. Ensino: as abordagens do processo. São Paulo: EPU, 1986. 
NASCIMENTO, A. M. S. et al. Dados Pauling: Um Jogo Didático no Conteúdo de Distribuição Eletrônica no Ensino de Química. In: $12^{\circ}$ Simpósio Brasileiro de Educação Química, 2014, Fortaleza - CE. Atas do Simpósio Brasileiro de Educação Química, 2014.

NASCIMENTO, A. M. S. et al. Dominós das Funções Oxigenadas: Um Jogo Didático no Conteúdo de Química Orgânica. In: 55² Congresso Brasileiro de Química, 2015, Goiânia GO. Anais do $55^{\circ}$ Congresso Brasileiro de Química, 2015.

NASCIMENTO, A. M. S. Jogo Didático no Ensino de Química Através do Ciclo da Experiência Kellyana (CEK). Vitória de Santo Antão, 2016. Monografia (Licenciatura Plena em Química). Vitória de Santo Antão, IFPE, 2016.

NUNES, A. S.; Adorni, D.S. O ensino de química nas escolas da rede pública de ensino fundamental e médio do município de Itapetinga-BA: O olhar dos alunos.. In: Encontro Dialógico Transdisciplinar - Enditrans, 2010, Vitória da Conquista, BA. - Educação e conhecimento científico, 2010.

ROBAINA, J.V.L. Química através do lúdico: brincando e aprendendo. Canoas: Ed. Ulbra, 2008, 480p.

SOARES, M. (2008). Jogos e Atividades Lúdicas no Ensino de Química: Teoria, Métodos e Aplicações. In: Anais do XIV Encontro Nacional de Química (XIV ENEQ). Curitiba, Brasil.

SOARES, M. H. F. B.; OKUMURA, F.; Carvalheiro, E. T. G. Proposta de um Jogo Didático para Ensino do Conceito de Equilíbrio Químico, Química Nova na Escola, 18, 13-17 (2003).

SOARES, M.H.F.B. O lúdico em química: jogos e atividades aplicadas ao ensino de Química. 2004. Tese (Doutorado) - Universidade Federal de São Carlos, São Carlos, 2004.

SOUZA, F. C. M., et al. Avaliação da aprednizagem por meio do jogo didático "Jogando limpo", nas aulas de Ciência. Ponta Grossa- Paraná, 2010.

VYGOTSKY, L. S. A formação social da mente: o desenvolvimento dos processos psicológicos superiores. Michael Cole et al (Org.) 4 Ed. São Paulo: Martins Fontes, 1987. 